\title{
FGM Architecture with Heat-Resistant Properties
}

\author{
Svetlana A. Oglezneva ${ }^{1,{ }^{*}}$, Maxim N. Kachenyuk ${ }^{1}$, and Andrey A. Smetkin ${ }^{1}$ \\ ${ }^{1}$ Perm National Research Polytechnic University, 614990, Perm, Russia
}

\begin{abstract}
A composite laminated heat-resistant material was manufactured by the method of spark plasma sintering. The architecture of a bonding layer between a substrate made of a heat-resistant superalloy and a ceramic coating containing sublayers of the intermetallic NiAl and a mixture of NiAl with 15 or 30 wt. \% zirconia (8YSZ) is proposed. In a layered composite, the microhardness and thermal conductivity change monotonically on going from the substrate to the outer ceramic. The coefficient of linear thermal expansion of the bonding layer is close to that for ceramics in the operating temperature range.
\end{abstract}

\section{Introduction}

Effective thermal protection of high-temperature components in modern gas turbines is achieved due to ceramic thermal barrier coatings (TBC) on the surface of nickel superalloy parts. Gradient heat-resistant material to ensure long-term operation should not have pronounced interfaces [1]. To form structures with similar properties, additional aluminum, silicon, hafnium, tantalum, etc. are introduced into the sublayer. [2-4] an additional sublayer of aluminum or platinum foil is created [5-6].

The purpose of this work was to obtain by the method of spark plasma sintering (SPS) and to study the binder between the superalloy and the external ceramic of the NiCrAlYYSZ system.

\section{Materials and research methods}

As a starting material for obtaining samples of a binder material for TZP used powder alloy $\mathrm{NiAl}$ of grade VKNA (JSC "Polema"), containing 21.97 wt. \% Al, 3.25 wt. \% Cr, 0.81 wt. $\% \mathrm{Co}, 0.76$ wt. \% Mo, W, Ti, Co as impurities, Ni - the rest.

For the formation of the outer coating, we used zirconium dioxide powder stabilized with $7.47 \mathrm{wt} \% \mathrm{Y}_{2} \mathrm{O}_{3}$ (YSZ) (specific surface area $59.3 \mathrm{~m}^{2} / \mathrm{g}$, average particle size $\mathrm{d}_{50}=$ $2.4 \mu \mathrm{m}$ ) obtained by the method of reverse coprecipitation according to the procedure [7]

To obtain a sublayer adjacent to the ceramic coating, composites $\mathrm{NiAl}+15 \mathrm{wt}$. \% YSZ and NiAl + 30 wt. \% YSZ were prepared. Layered samples were obtained on a Dr. SinterSPS-1050b (SPS Syntex Inc.) in $15 \mathrm{~mm}$ graphite mold. Spark plasma sintering was

\footnotetext{
*Correspondingauthor:svetlana.iron@yandex.ru
} 
performed at a heating rate of $120^{\circ} \mathrm{C} / \mathrm{min}$ with isothermal holding at $1070{ }^{\circ} \mathrm{C}$ for 5 minutes, a pressure of $30 \mathrm{MPa}$.

The thermal conductivity was measured on an IT- $\lambda-400$ device in the temperature range of $50-300{ }^{\circ} \mathrm{C}$ on samples with a diameter of $15 \mathrm{~mm}$ and a height of about $5 \mathrm{~mm}$. The coefficient of linear thermal expansion of materials of various compositions in the temperature range of $100-800^{\circ} \mathrm{C}$ was determined on a SetSys Evolution 24 (Setaram) device at a heating rate of $10 \mathrm{~K} / \mathrm{min}$.

The structure of powders and sintered samples was investigated using a Vega3 Tescan (Tescan) scanning electron microscope combined with an Advanced Aztec Energy system for analyzing the elemental composition of materials (Inca Energy 350, Oxford Instruments) based on an X-MAX50 energy dispersive detector with a resolution no worse than $127 \mathrm{eV}$. Microhardness was determined according to the standard method according to GOST $9450-76$ at a load of $50 \mathrm{~g}$.

Thermal cycling of sintered samples of TZP on Inconel 625 and sublayers with different YSZ content was carried out in a muffle furnace in air. The samples were placed in an oven heated to $1100^{\circ} \mathrm{C}$, held for $10 \mathrm{~min}$, then removed from the oven and cooled in air to room temperature for $30 \mathrm{~min}$. After each cycle, the surface was visually inspected to determine the appearance and development of cracks on the outer ceramic layer. The process was repeated until the damage to the visible area of the upper layer reached $5 \%$.

\section{Experimental results and discussion of studies}

Energy dispersive spectroscopy (EMF) of the structure showed that dark gray grains, in addition to the $\gamma-\mathrm{Ni}(\mathrm{Cr})$ phases of the solid solution and $\beta$-NiAl, in their volume and along their boundaries contain components of refractory elements in the form of bright inclusions related to cobalt, titanium, tungsten and molybdenum (Fig. 1). In the binder sublayer containing 15 or $30 \%$ YSZ, the ceramic particles have a dark color (Fig. 1). Tungsten is predominantly located along the grain boundaries. When passing from the NiAl layer to the $\mathrm{NiAl}+15$ wt. \% YSZ and $\mathrm{NiAl}+30$ wt. \% YSZ layer, the microhardness increased from 305 to $435 \mathrm{HV} 0.05$ and $650 \mathrm{HV} 0.05$, respectively. In the $30 \mathrm{wt} \%$ YSZ specimen, the microhardness is higher and the scatter of its values is greater due to the higher content (Fig. 2).

The thermal conductivity of Inconel 625 corresponds to $16.5 \mathrm{~W} / \mathrm{m} \cdot \mathrm{K}$ [8], and the thermal conductivity of YSZ, determined by us at the same temperature $\left(100^{\circ} \mathrm{C}\right)$, is $1.8 \mathrm{~W}$ $/ \mathrm{m} \cdot \mathrm{K}$, which coincides with the data [9]. The thermal conductivity values of $\mathrm{NiAl}+15$ wt. \% YSZ and NiAl +30 wt. \% YSZ samples take intermediate values between the thermal conductivity of NiAl and YSZ (Fig. 3). Thus, the layers NiAl + 15 wt. \% YSZ and NiAl + $30 \mathrm{wt}$ \% YSZ form a thermal conductivity gradient when going from the superalloy to the outer ceramic.

The coefficient of linear thermal expansion (CLTE) YSZ takes values of (10...11) $10^{-6}$ $\mathrm{K}^{-1}$, depending on the composition [10]. In the samples $\mathrm{NiAl}+15 \mathrm{wt} \% \mathrm{YSZ}$ and $\mathrm{NiAl}+30$ wt. $\%$ YSZ in the temperature range $800-1000{ }^{\circ} \mathrm{C}$ the CLTE is about $12 \cdot 10^{-6} \mathrm{~K}^{-1}$, significantly approaching the CTE of ceramics. It is likely that in the sublayers containing 15 or $30 \mathrm{wt}$. \% YSZ, the decrease in LTEC is due to the weak interfacial interaction of the metal matrix with the ceramic.

Thermal cycling of the samples at $1100^{\circ} \mathrm{C}$ showed that, regardless of the YSZ content in the NiAl sublayer, the first main crack was found after 10 cycles. In this case, the formation of a network of cracks was not observed until 41 cycles, the coating is not destroyed. According to the results of metallographic analysis, the proportion of cracks relative to the total surface of the TBC does not exceed $5 \%$. Thus, thermal cycling has 
shown that the architecture of a protective material for a superalloy considered in this work is quite promising.

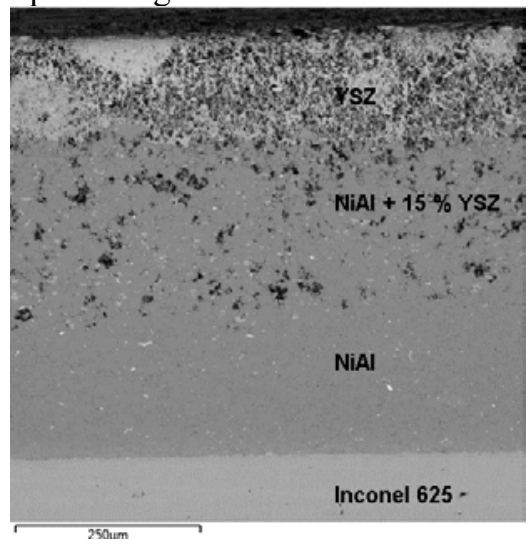

a

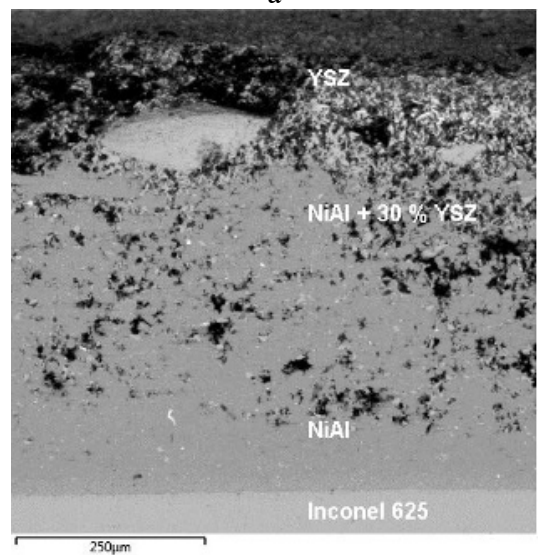

c

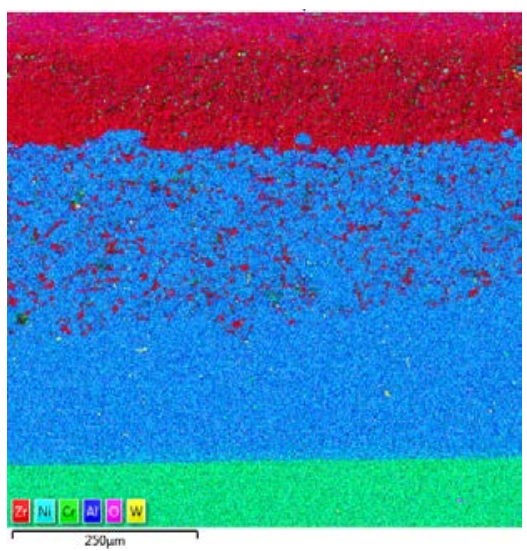

$\mathrm{b}$

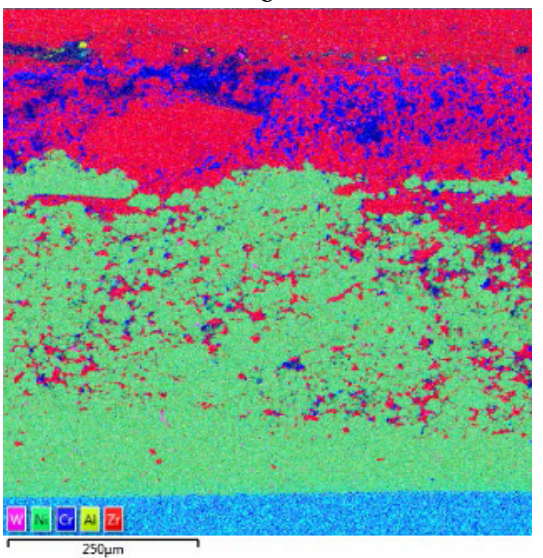

d

Fig. 1. SEM images of thin sections and distribution maps of elements of layered samples $\mathrm{NiAl}+15$ wt. \% YSZ (a, b) and NiAl +30 wt. \% YSZ (c, d).

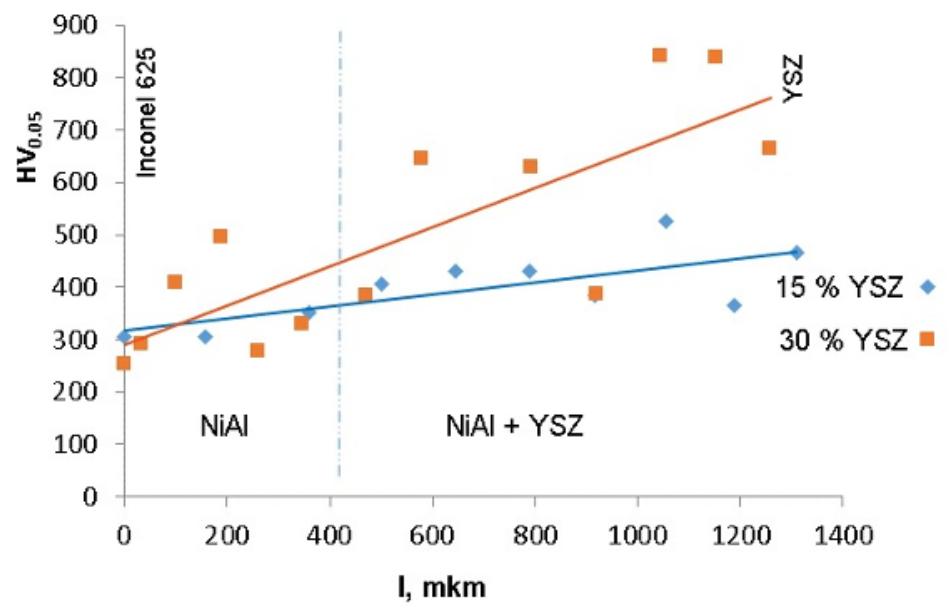

Fig. 2. Microhardness at the interface between the layers $\mathrm{NiAl} / \mathrm{NiAl}+15$ wt. $\% \mathrm{YSZ}$ and $\mathrm{NiAl}+30$ wt. \% YSZ in the cross section. 


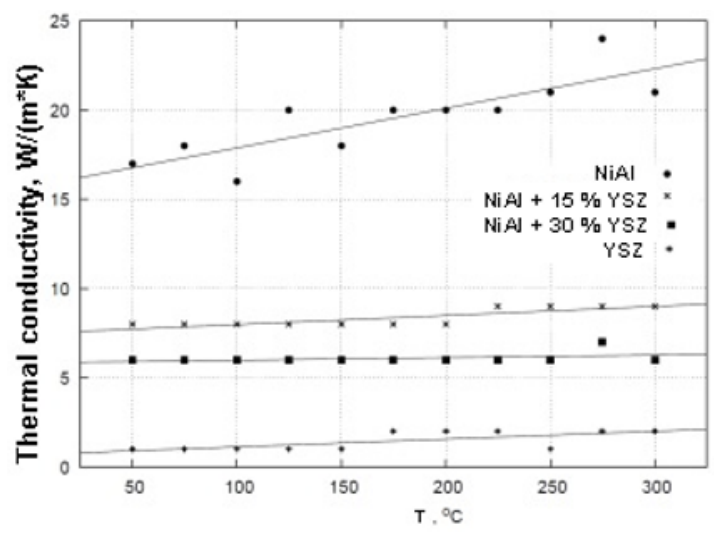

Fig. 3. Dependence of thermal conductivity on sample temperature.

\section{Conclusion}

For the formation of a heat-shielding coating on the Inconel 625 alloy, a binder material consisting of sublayers of NiAl and NiAl + 15 (30) wt. \% YSZ has been proposed. Spark plasma sintering makes it possible to obtain high-density of material in one technological mode at $\mathrm{T}=1070{ }^{\circ} \mathrm{C}$, pressure of $30 \mathrm{MPa}$ and isothermal holding for 5 minutes. The resulting binder sublayers do not have pronounced interfaces between themselves and with the outer ceramic YSZ layer.

The heat-shielding material has a thermal conductivity gradient from $16.5 \mathrm{~W} / \mathrm{m} \cdot \mathrm{K}$ (NiAl layer) to $1.8 \mathrm{~W} / \mathrm{m} \cdot \mathrm{K}$ (external ceramics). The YSZ content in the binder sublayer affects the coefficient of linear thermal expansion. CLTE with an increase in temperature to $1000^{\circ} \mathrm{C}$ decreases from $15 \cdot 10^{-6} \mathrm{~K}^{-1}$ to $12 \cdot \cdot 10^{-6} \mathrm{~K}^{-1}$. Thermal cycling at $1100^{\circ} \mathrm{C}$ for 41 cycles did not lead to destruction of the coating; only single cracks were formed along the edge of the samples.

The study of the reduction of the sublayer with the outer ceramic layer was carried out within the framework of the state assignment of the Ministry of Education and Science of Russia to carry out fundamental scientific research (Topic "Development of theoretical and technological foundations and digital technologies for the design of functional composite materials, multifunctional nanocoatings and diagnostic information systems for monitoring highly loaded elements of aircraft structures", No. FSNM -2020-0026).

The reported study of formation of ceramic lay was funded by RFBR and Perm Territory according to the research project № 19-48-590007.

\section{References}

1. D.S. Kashin, P.A. Stekhov, Modern heat-shielding coatings obtained by electron-beam sputtering (review), Proceedings of VIAM, v. 2(62), pp.84-90 (2018)

2. A. Haynes, K.A. Unocic, M.J. Lance, B.A. Pint, Impact of superalloy composition, bond coat roughness and water vapor on TBC lifetime with HVOF NiCoCrAlYHFSi bond coatings, Surface and Coatings Technology, v.237, pp. 65-70 (2013)

3. X. Zhou, Z. Xu, R. Mu, L. He, G. Huang, X Cao, Thermal barrier coatings with a double-layer bond coat on Ni3Al based single-crystal superalloy, Journal of Alloys and Compounds, v.591, pp. 41-51 (2014) 
4. H.Z. Yang, J.P. Zou, Q. Shi, M.J. Dai, S.S. Lin, W. Du, L Lu, Analysis of the microstructural evolution and interface diffusion behavior of NiCoCrAlYTa coating in high temperature oxidation, Corrosion Science, v.153, pp.162-169 (2019)

5. J. Song, K. Ma, L. Zhang, J. M. Schoenung, Simultaneous synthesis by spark plasma sintering of a thermal barrier coating system with a NiCrAlY bond coat, Surface and Coatings Technology, v. 205(5), pp. 1241-1244 (2010)

6. D. Monceau, D. Oquab, C. Estournès, M. Boidot, S. Selezneff, N. Ratel-Ramond, Thermal barrier systems and multi-layered coatings fabricated by spark plasma sintering for the protection of Ni-base superalloys, Materials Science Forum, v. 654656, pp. 1826-1831 (2010)

7. V.B. Kul'met'eva, S.E. Porozova, E.S. Gnedina, Synthesis of nanocrystalline zirconium dioxide stabilized with yttrium oxide for low-temperature sintering, Russian Journal of Non-Ferrous Metals, v. 54(3), pp. 239-245 (2013)

8. E. Kaschnitz, L. Kaschnitz, S. Heugenhauser, Electrical Resistivity Measured by Millisecond Pulse Heating in Comparison with Thermal Conductivity of the Superalloy Inconel 625 at Elevated Temperature, International Journal of Thermophysics, v.40(3), pp. 27-40 (2019)

9. K.W. Schlichting, N.P. Padture, P.G. Klemens, Thermal conductivity of dense and porous yttria-stabilized zirconia, Journal of Materials Science, v.36, pp. 3003-3010 (2001)

10. L. Guo, Y. Zhang, C. Wang, X. Zhao, F. Ye, Phase structure evolution and thermal expansion variation of $\mathrm{Sc}_{2} \mathrm{O}_{3}$ doped $\mathrm{Nd}_{2} \mathrm{Zr}_{2} \mathrm{O}_{7}$ ceramics, Materials \& Design, v. 82, pp. 114-118 (2015) 